\title{
The Importance of User Roles in Feature Bundling Decisions in Wireless Handheld Devices \\ Strategic User Needs Analysis (SUNA)
}

\author{
Sheila Narasimhan and Gitte Lindgaard \\ Human Oriented Technology Lab (HotLab) \\ Dept of Psychology, Carleton University, Ottawa, Ontario, Canada, K1S 5B6 \\ snarasim@chat.carleton.ca and gitte_lindgaard@carleton.ca
}

\begin{abstract}
The bundling of features in wireless technologies is considered to be a significant issue by market analysts and service providers. Currently, there is a proliferation of handheld devices such as Personal Digital Assistants (PDAs) making it very difficult for users to select the devices that match their needs. A literature review suggests that although feature bundling in handheld sets and services is a critical decision in product and service development, it is often left to chance. This paper indicates that for a smooth deployment of wireless technologies, it is important to study the needs of users from the perspective of the roles for which they use the handheld device. Specifically, this paper describes the development and testing of a methodology for supporting the selection and bundling of features in wireless technologies such as Personal Digital Assistants (PDAs). The methodology, termed Strategic User Needs Analysis (SUNA), combines several investigative methods from $\mathrm{HCI}$ and market research with an emphasis on User Role Modelling (Constantine \& Lockwood, 1999). Initial testing of SUNA on a small sample of users, representing two focal user roles, indicates that the methodology is effective in identifying features most needed for the two focal roles. It identified the relevant characteristics, usage patterns, similarities and differences between these, and their consequent implications for feature bundling by product designers and developers.
\end{abstract}

Key words: Personal digital assistants, wireless technologies, user needs assessment, role modelling, job analysis, features bundling. 


\section{INTRODUCTION}

User needs and task analyses occupy an important position in Human Computer Interaction (HCI) literature. A review of several methods (Beyer \& Holtzblatt, 1998; Hackos \& Redish, 1998; Maguire, 1997; Mayhew, 1999) indicates that there is a strong focus on user task analysis techniques. These techniques describe user tasks, as they are performed (e.g. Shepherd, 2001; Kirwan \& Ainsworth, 1992), in great detail, and are, therefore, not ideally suited to identifying the features and services critical to each group or segment of users. Secondly, these methodologies assume implicitly or explicitly that the purpose and functions of the system in question are already known and that the tasks it is intended to support have been determined. This assumption in turn renders them less appropriate for Greenfield applications. Even methodologies that take users' work context into account (e.g. Beyer \& Holtzblatt, 1998) assume that users are readily accessible and that they can be interrupted while performing tasks. However, this tenet does not hold for mobile workers and travelling executives whose jobs do not lend themselves to intrusive inquiry methods proposed in task analysis methodologies. The selection and bundling of features is an important planning task in the product design and development stage, which requires strategic information on usage patterns, behaviour and needs of users within distinctive, identifiable groups. Since task analysis fails to provide this higher-level information, it is important to look at other methods.

A review of marketing literature was undertaken to identify appropriate investigative techniques for feature bundling. The review revealed that industry analysts mainly focus on market predictions (Yankee Group, 1999). Their methodologies are grounded in market research techniques, which are "about studying people as "customers" and "consumers" especially their own views of their needs and desires, their preferences and their reactions to new ideas" (Hackos \& Redish, 1998, p.17).

Given that the HCI and market methods did not offer an immediate solution to the issue of feature bundling, it became necessary to develop and test a methodology, which would identify user needs at a strategic level based on product usage patterns, rather than on user performance in predetermined tasks. Specifically, it was important to identify those factors, which distinguish one group of users from another in terms of the desired bundle of features in Personal Digital Assistants (PDAs). Several investigative techniques were combined, adapted, and applied here to meet this challenge. We call the resulting approach Strategic User Needs Analysis (SUNA) to highlight the fact that it is a strategic planning tool. The paper outlines SUNA and its possible application to support PDA feature bundling. 


\section{METHODOLOGY}

Constantine and Lockwood's (1999) notion of user role modelling offered a sound investigative technique to link usage patterns, user behaviour and user needs to their respective roles. The user role model is defined as an abstract collection of user needs, interests, expectations, behaviours, and responsibilities. This abstract collection of information about the user is used to describe the relationship of the user to the system (PDAs) and subsequently his or her needs stemming from the roles.

A brainstorming session was initiated to accomplish a variety of tasks in a group setting. The tasks are shown in Figure 1.

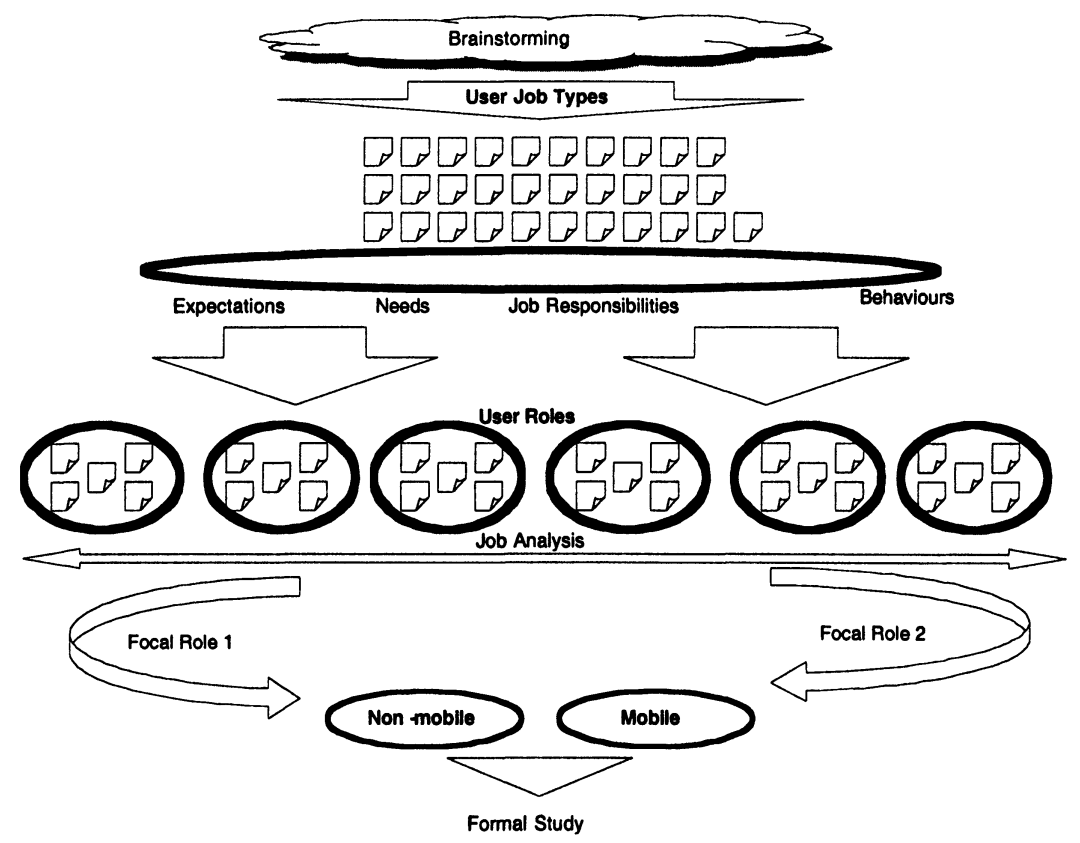

Figure 1: Brainstorming session tasks

The first step involved the listing of user job types. The user job types listed were then clustered into user roles on the basis of the needs, expectations, behaviours and job responsibilities of each job type. Six user roles were identified from 31 job types. A job analysis using job descriptions and specifications from two companies was undertaken to confirm that the clustering was in fact valid. Two focal roles were then selected for the formal field study. 
In the field study, a sample of participants representing the user roles identified in the brainstorming session was observed to identify usage patterns and behavioural characteristics. An automatic software log on the participants' PDAs recorded their usage of the various functions over two days. Some users had to fill in their usage manually in a diary because their PDAs were not compatible with the software for automatic logging of usage. An open-ended interview was conducted with each participant using an instrument developed specifically for this purpose.

\section{IDENTIFYING USER/JOB TYPES}

Seven PDA users representing a variety of disciplines such as, human resources, administration, IT, marketing and software development in a large telecommunications company participated in the brainstorming session. The session commenced with a brief description of the research purpose as well as its significance in the bundling of PDA features using the role model approach. The concepts of user types and user roles were then described. Each participant was asked to read and sign an informed consent form. To generate as many user types as possible, participants were asked to write the names of as many user/job types as they could think of on post-it notes, with one type per note. Participants took turns pasting their roles on a board. Duplicates were eliminated, leaving a list of unique user/job type names. A total of 31 user types were generated in this fashion as shown in Table 1 below.

\begin{tabular}{lll}
\hline & \multicolumn{1}{c}{ User Types } \\
\hline Administrative Assistants & IT support & Security \\
Babysitters/Caregivers & Marketing Researchers & Servers \\
Delivery People & Military Personnel (RCAF) & Small Business Owners \\
Designers (R\&D) & Paramedics & Stock Brokers \\
Dispatchers & Professors & Students \\
Doctor & Real Estate Agents & Team leaders and executives \\
Emergency Personnel & Reporters/Journalists & Transportation Personnel \\
Field technicians & Researcher & Travel Agents \\
Globe trotters & Restaurant/Hotel Clients & Travel/Tour Guides \\
HR Professionals & Sales representative & Travelling executives \\
& & Ultra light Pilots \\
\hline
\end{tabular}

Table 1. User types generated by brainstorming 


\subsection{Deriving User Roles}

Abstract user roles have to be derived from specific user/job types using a bottom-up approach (Constantine \& Lockwood, 1999). The participants were asked to group the 31-user/job types on the basis of the perceived needs, expectations, behaviours, and job responsibilities associated with each job type. Needs were defined as requirements for the device, such as the need to receive e-mail or text messages. Behaviour reveals the expected frequency and volume of usage. Expectations reflect the user's expectations of device reliability and transmission speed, access to the network, and his/her mobility. Relevant job responsibilities are identified by listing typical activities that a person would perform in the particular role, such as contacting customers or the work base, checking inventory or accessing a given dynamic database. Grouping of user/job types continues until all similar roles are grouped together and the resulting roles are distinct.

The participants after much discussion grouped user/job types into generic or abstract categories of user roles. The resulting user roles were further validated through an analysis of the needs, expectations, behaviours, and relevant job responsibilities found in formal job classification documents obtained from the Human Resources departments of two organisations. The 31 user/job types identified in this study were finally reduced to a set of six categories of user roles: field service, travel routing, database access, nonmobile professionals, mobile professionals, and multiple roles.

\subsection{Designating Focal User Roles}

From the six user roles, two focal user roles were to be selected for further study. Focal roles are those viewed to be critical for the PDA market, specifically with respect to the feature bundling of PDAs. Because PDAs are in the early stages of the product life cycle, the discussion focused on user roles representing early adopters. The corporate business market, as opposed to individual consumers, was identified in broad terms as a leading segment with a larger number of innovators and early adopters of PDAs.

Within the corporate business market sector, senior managers/executives were seen as early adopters given their high level of mobility and/or their constant need for time critical information for fulfilling their role. The two critical roles selected were thus mobile and non-mobile professionals. Examples of the perceived needs, expectations, behaviours and relevant job responsibilities pertaining to some representatives of these categories are shown in Table 2 below. Complete details may be found in Narasimhan (2001). 


\begin{tabular}{|c|c|c|c|c|c|}
\hline $\begin{array}{l}\text { User } \\
\text { role }\end{array}$ & User type & Needs & $\begin{array}{l}\text { Expectatio } \\
\text { ns }\end{array}$ & $\begin{array}{l}\text { Behaviour } \\
\mathbf{s}\end{array}$ & $\begin{array}{l}\text { Job re- } \\
\text { sponsibility }\end{array}$ \\
\hline \multirow[t]{2}{*}{$\begin{array}{l}\text { Non- } \\
\text { mobile }\end{array}$} & $\begin{array}{l}\text { Administrative } \\
\text { assistants }\end{array}$ & $\begin{array}{l}\text { Scheduler } \\
\text { Communicate } \\
\text { with manager } \\
\text { Manage } \\
\text { meetings and } \\
\text { events } \\
\text { Travel info } \\
\text { Contact lists }\end{array}$ & $\begin{array}{l}\text { Scheduling } \\
\text { capability } \\
\text { Access to } \\
\text { internal/ } \\
\text { external } \\
\text { databases } \\
\text { Reliable } \\
\text { device }\end{array}$ & $\begin{array}{l}\text { Frequent } \\
\text { usage } \\
\text { Moderate } \\
\text { volume }\end{array}$ & $\begin{array}{l}\text { Carry out } \\
\text { admin duties } \\
\text { to free up } \\
\text { time for the } \\
\text { group }\end{array}$ \\
\hline & Dispatchers & $\begin{array}{l}\text { Routing } \\
\text { information } \\
\text { Contextual } \\
\text { information } \\
\text { Relay info to } \\
\text { field } \\
\text { personnel }\end{array}$ & $\begin{array}{l}\text { Must be } \\
\text { fast, reliable } \\
\text { and have } \\
\text { database } \\
\text { access } \\
\text { (wireless } \\
\text { necessary?) }\end{array}$ & $\begin{array}{l}\text { Frequent } \\
\text { usage } \\
\text { High } \\
\text { volume }\end{array}$ & $\begin{array}{l}\text { Communicat } \\
\text { e and relay } \\
\text { info to field } \\
\text { personnel }\end{array}$ \\
\hline \multirow[t]{2}{*}{ Mobile } & Stock brokers & $\begin{array}{l}\text { Stock quotes } \\
\text { Contact lists } \\
\text { E-trade } \\
\text { Client } \\
\text { portfolio } \\
\text { Stock analysis }\end{array}$ & $\begin{array}{l}\text { Accurate, } \\
\text { real-time, } \\
\text { fast access, } \\
\text { secure, } \\
\text { portable, } \\
\text { reliable }\end{array}$ & $\begin{array}{l}\text { Frequent } \\
\text { usage } \\
\text { Moderate } \\
\text { volume }\end{array}$ & $\begin{array}{l}\text { Stay in touch } \\
\text { with markets } \\
\text { and clients } \\
\text { Conduct } \\
\text { transactions }\end{array}$ \\
\hline & $\begin{array}{l}\text { Reporters/ } \\
\text { Journalists }\end{array}$ & $\begin{array}{l}\text { Address book } \\
\text { Contact list } \\
\text { Schedule } \\
\text { Travel logs } \\
\text { Routing info } \\
\text { Research info }\end{array}$ & $\begin{array}{l}\text { Accurate, } \\
\text { fast, real- } \\
\text { time, global } \\
\text { access, file } \\
\text { transfer, } \\
\text { secure } \\
\text { intranet/ } \\
\text { internet }\end{array}$ & $\begin{array}{l}\text { Frequent } \\
\text { usage } \\
\text { Low- } \\
\text { moderate } \\
\text { volume }\end{array}$ & $\begin{array}{l}\text { Gather news } \\
\text { Report to } \\
\text { news room in } \\
\text { real time }\end{array}$ \\
\hline
\end{tabular}

Table 2. Needs, expectations, behaviours, and job responsibilities for a subset of mobile and non-mobile professionals 


\subsection{Analysing Usage Patterns}

The usage patterns common to the six user roles were derived from the results of the brainstorming session and the job analysis. Three dimensions of usage emerged from the information: extent of mobility, volume of action/transactions in the field, and amount of information transferred. Each dimension was measured in a qualitative manner using a low, medium and high scale. A summary of this analysis for non-mobile and mobile professionals is shown in Table 3 below. Details of all others are available in Narasimhan (2001).

\begin{tabular}{|c|c|c|c|c|c|c|c|c|c|}
\hline & \multicolumn{3}{|c|}{ Mobility } & \multicolumn{3}{|c|}{$\begin{array}{l}\text { Action/ } \\
\text { transaction }\end{array}$} & \multicolumn{3}{|c|}{$\begin{array}{l}\text { Amount of } \\
\text { information }\end{array}$} \\
\hline & $\mathrm{L}$ & M & $\mathrm{H}$ & $\mathrm{L}$ & $\mathbf{M}$ & $\mathrm{H}$ & $\mathrm{L}$ & $\mathbf{M}$ & $\mathrm{H}$ \\
\hline Non-mobile professionals & $\checkmark$ & & & & $\checkmark$ & & & & $\checkmark$ \\
\hline Mobile professionals & & & $\checkmark$ & & & $\checkmark$ & & $\checkmark$ & \\
\hline
\end{tabular}

Table 3. User role usage patterns

As the Table shows, the two focal user role categories differed on all three dimensions. While non-mobile professionals' usage patterns were indicative of transferring large amounts of information, hence a bandwidth issue, mobile professionals required the convenience of a portable, easy to carry PDA, with high speed of access, capable of completing transactions.

The results of the brainstorming session culminated in successful selection of two focal roles representing the early adopters of new wireless technological innovations such as PDAs. The methodological focus on user roles and their relationship to PDAs rather than on individual users enabled a higher level of abstraction necessary for the purpose of strategic bundling.

\subsection{Initial Field Testing}

The field study involved observing usage patterns of mobile and nonmobile professionals representing the two focal user roles selected at the end of the brainstorming session. Twelve users of mobile technologies, six from each focal user role group participated in the study. The participant's usage of the various functions of the PDAs was recorded automatically through the use of a software program that was beamed on to their device. Exceptions were made in the case of a cellular phone user and a RIM Blackberry user, since their PDAs were incompatible with the automatic usage logging software. These individuals recorded usage on a log sheet. The device usage 
of all participants was captured over a two-day period. At the end of the two days, participants were interviewed individually in their own office. The logged data was used as a reference to jog the user's memory with respect to the purpose of the use, the type of communications established, and the features necessary to assist the role. The data log thus provided a realistic setting for assessing the user role and the relationship of the PDA in assisting the user role. This is similar to Beyer and Holtzblatt's (1998) notion of an 'artifact model' in which an artifact is used to jog the user's memory for the analyst to understand the work the user is trying to accomplish with the system in question.

A set of 30 open-ended questions addressing six research questions was developed and administered in each interview:

1. What are users in this role trying to accomplish?

2. Which PDA functions are used most frequently?

3. What is the relationship of the PDA functions to the user role?

4. What other devices are used to accomplish what the user wants?

5. Gaps preventing the user from completing the work in the user role

6. Existing features and users' wish list

\section{RESULTS}

\subsection{User Roles and Sub-Roles}

Participants were asked to identify the four main functions, or sub-roles, they fulfil in their current job. Analysis of responses indicated that the following functions involved the use of PDAs: Communicator, Leader \& Manager, Administrator, Analyst \& Researcher, Creator \& Developer, and Field operator. The description of sub-roles indicated that the non-mobile professionals' main functions tended to be internally oriented towards the organisation, whereas the mobile professionals' functions tended to be outwardly oriented towards clients. Since mobile professionals are away from the office, there seems to be a greater emphasis on communication capabilities of PDAs, whereas the non-mobile professionals focussed more on the PDA's administrative functions. It will also be recalled that the mobile and non-mobile professional roles varied in usage dimensions (volume and frequency of transactions). These differences in roles and usage patterns are indicative of two user roles that could form the basis for features bundling in PDAs and other wireless technological innovations. High-level functions that could be supported by PDAs were then identified from the participants' descriptions. These are presented in Table 4 below. 


\begin{tabular}{|c|c|}
\hline $\begin{array}{l}\text { Main job } \\
\text { function }\end{array}$ & PDA-supportable functions \\
\hline Communicator & $\begin{array}{l}\text { Time management, People management, Communication, People } \\
\text { interaction (partner, secretary, staff), Customer contact, Client work } \\
\text { (consulting), Client relationships, Presentations }\end{array}$ \\
\hline Leader\& & Project management, Office management (finance, recruiting), \\
\hline Manager & Leadership role (manage marketing/sales group) \\
\hline Administrator & $\begin{array}{l}\text { Operational strategy, Hiring staff, Document management, Time } \\
\text { management, Admin/Evaluation }\end{array}$ \\
\hline Analyst\& & N/A \\
\hline Researcher & \\
\hline Field operator & Design \\
\hline
\end{tabular}

Table 4. Possible PDA features supporting non-mobile and mobile professionals $(\mathrm{n}=12)$

\subsection{PDA Functions Used Frequently by Focal Roles}

Based on the data logs and memory, the most frequently used features for non-mobile professionals included the date book, Quicksheet (spreadsheet), address book, memo pad, and calculator. On the other hand the frequently used features for mobile professionals included the date book, address book, e-mail, memo pad, to do list, and cell phone.

Given the high mobility of their roles, mobile professionals tended to use their PDAs as a mobile office to network with their own head office and their clients (e-mail, cell phone). It is interesting to note that the non-mobile professionals with their well-equipped offices with telephones and PCs did not use the networking functions in their PDAs. Even when these commonly used functions are available in mobile devices, these early adopters in the non-mobile category still primarily use traditional devices perhaps due to cost considerations.

\subsection{Linkage of PDA Functions to the User Role}

Table 5 provides the reasons for which the PDA functions are used by the two user roles. The information in the Table indicates that certain commonalities prevail across the two groups, although some functions are used differently. For example, whereas non-mobile professionals use the date book for administrative purposes, mobile professionals use it for time 
management. Similarly, the non-mobile user role uses the address book as much for addresses as for phone numbers, whereas the mobile user role uses it mainly as a quick reference to phone numbers. To the mobile user operating in an environment that allows integration of voice and data, access to remote and local databases, and linkage of the date book and address book with e-mail and telephone functions would add considerable value. Nonmobile professionals may not need these converging meta-functions unless they also changed their usage patterns to rely more on mobile than on desktop technologies. The observation that the non-mobile professionals do not use e-mail or the to do list in their PDA reinforces the notion that, at this point in time, they do not quite see the PDA as a substitute for traditional devices.

\begin{tabular}{|c|c|c|}
\hline Function & Non-mobile & Mobile \\
\hline Date book & $\begin{array}{l}\text { Make appointments, schedule, } \\
\text { reminder, coordinate meetings }\end{array}$ & $\begin{array}{l}\text { Time management (alerts, } \\
\text { beeps) }\end{array}$ \\
\hline $\begin{array}{l}\text { Address } \\
\text { book }\end{array}$ & Internal/external addresses, phone & $\begin{array}{l}\text { Quick reference to phone } \\
\text { numbers }\end{array}$ \\
\hline Memo pad & Business/personal use & Business notes in field \\
\hline Calculator & Calculations & -- \\
\hline Quicksheet & Class attendance, marking & -- \\
\hline E-mail & --- & $\begin{array}{l}\text { Communicate with office, } \\
\text { clients }\end{array}$ \\
\hline To Do list & -- & $\begin{array}{l}\text { Organize business and } \\
\text { personal affairs }\end{array}$ \\
\hline Cell phone & -- & sole phone contact \\
\hline
\end{tabular}

Table 5. PDA function usage in the two user roles

\subsection{Other Devices Used In Concert With PDAs}

Non-mobile professionals use computers (PC, laptop), telephones (terrestrial, cell), and paper in conjunction with the PDA. The address book is used in conjunction with telephones, linking the administrator and communicator roles. The memo pad is used in concert with the PC primarily 
to back up the memo pad entries, which may consist of items such as meeting and presentation notes.

Mobile professionals use the date book and the address book in conjunction with voice communication devices, again linking the administrator and communicator roles. The address book is also used with the laptop to update/backup administrative information. The laptop is used for e-mail, and the memo pad is backed up in a "Hotsync" operation.

\subsection{Gaps In PDA Functions In Fulfilment Of User Roles}

In the non-mobile role, the key gaps identified with the Palm and Handspring related to visual factors, battery life, and software-related functions. The following gaps in PDAs were noted:

- Handwriting difficulties, e.g. lack of an on-line reference for the graffiti language and poor character recognition

- Screen deficiencies, e.g. small size, poor back lighting, reflection, low resolution

- Poor battery life

- Difficulties finding, downloading, and integrating additional software In the mobile role, the distinctive issues related to ergonomics, convenience, and absence of cross-functional and communication capabilities. Issues raised by mobile users (PDAs, Blackberry, cell phone) were:

- Handwriting/typing difficulties, e.g. poor character recognition, small keyboard, no graffiti (Blackberry), numeric keypad on the cell phone

- Screen deficiencies, e.g. small size, poor back lighting, reflection, low resolution

- Poor battery life

- Devices hard to grip

- Lack of inter-linking capabilities between functions, e.g. no link from date book to contact list

- Inconvenient e-mail function on the Blackberry and the cell phone, e.g. emails must be trimmed, cell phone and office e-mail addresses are different, and responding to e-mails is difficult because of scrolling

- Poor hotsync/synchronisation operation to the PC, e.g. fields are not matched

\subsection{Perceived Value of PDA Features}

A wish list of what participants would like to see in the later models of PDAs was obtained. Some differences between the non-mobile and mobile professional roles were noticed. Non-mobile professionals wanted to include 
phone, e-mail, voice memo, instant messaging, and banking features to facilitate the office role at home. The mobile professionals wanted to integrate the PDA with wireless connectivity and the Blackberry with Graffiti handwriting. They also mentioned GPS, unified messaging, information services for maps and stock quotes, e-wallet allowing credit or debit card information, and a high-speed broadband wireless connection. One can see from the wish list that both user roles tend to get more sophisticated with a key emphasis on convergence from mobile professionals.

In addition to a wish list, participants were also asked to rate existing and suggested new features for importance on a 5-point rating scale ranging from 'very unimportant' (1) to 'very important' (5). Results of this exercise are shown in Table 6 below. Features were grouped into 'ergonomics', functions', and 'access'. 'Ergonomics' refers to physical design issues, 'functions' refers to features that do not require network connectivity, and 'access' represents those features that require such connectivity.

\begin{tabular}{llrc}
\hline Category & Element & $\begin{array}{c}\text { Mobile } \\
(\mathrm{n}=6)\end{array}$ & $\begin{array}{c}\text { Non-mobile } \\
(\mathrm{n}=6)\end{array}$ \\
\hline Ergonomics & PDA size & 6 & 5 \\
& Screen size & 6 & 4 \\
\hline Feature & Address book & 6 & 5 \\
& Scheduler & 6 & 6 \\
& Alarm & 1 & 4 \\
& To Do list & 3 & 4 \\
\hline Access & Phone & 6 & 3 \\
& Voice mail & 6 & 3 \\
& Wireless connectivity & 4 & 1 \\
& Information services & 4 & 0 \\
& E-mail & 4 & 2 \\
& E-wallet & 3 & 4 \\
& GPS & 2 & 1 \\
& Internet & 2 & 1 \\
& Intranet & 2 & 0 \\
& E-commerce & 1 & 1 \\
& Banking & 0 & 2 \\
& Voice memo & 0 & 3 \\
& Fax & 0 & 0 \\
& Unified messaging & 0 & 2 \\
\hline
\end{tabular}

* Note: Features rated 4 or 5 by more than half of the participants are shaded

Table 6. * Number of participants rating features 'Important' (4) or 'Very important' (5) 
As the Table shows, ergonomic issues were considered important to both groups of participants. All the features, such the address book, scheduler, alarm were considered important to the non-mobile user role. Only three users in the mobile user role considered the to do list as important eventhough the to do list was among the most frequently used functions. It seems surprising also that the alarm was considered important by most of the non-mobile professionals but only by one of the mobile professionals, as this had not been noted among the most frequently used functions. Clearly, those 'access' functions that enable direct person-to-person contact were important to the mobile, but not to the non-mobile professionals. It appears that relative to the access functions the administrative functions were less important to the mobile professional role. The observation that neither group found the information-rich access features, such as internet/intranet access, important probably reflects one of the limitations of small monochrome screens and the fact that both groups have access to PCs and/or laptops from their own or other offices and hotels. Thus, the PDA appears to play a role of convenience rather than being seen as a replacement of services that are also available via other means.

The above data should be interpreted with caution. The sample is small, the data collection period was only two days, and, although some data were collected from electronic logs, the lack of accuracy between people's wishes and their estimates of their own 'typical' usage is well documented (Lindgaard, 1993; Lindgaard \& Ferguson, 1992).

\section{DISCUSSION}

While segmentation and feature bundling to differentiate a product or service on the basis of segment needs is the goal of every product manufacturer and service provider, the robustness of the research methods employed to identify the distinctive user groups and their needs often appear questionable. The objective of this research was to identify and test a methodology that would be helpful in relating features of wireless technological innovations such as the PDA to different groups of users with distinctive roles and usage patterns. The challenge was to identify target user groups who represent early adopters of new technology, to understand and document their needs such that information thus gleaned could be applied to selecting features for future technologies.

The notion of 'user roles' as described by Constantine and Lockwood (1999) was central to the methodology outlined above. The focus on roles allowed for a strategic abstraction of user needs from an individual level to a group level. Inherently, successful feature bundling very much depends on 
identifying segments that are not only early adopters but also are distinguishable so that they can be targeted. The proposed methodology rests on the role(s) users occupy rather than on their individual habits and preferences. It facilitates the subsequent selection of users for further study during the UNA, and it enables product \& service designers to focus on the common elements of target user groups.

Within Constantine and Lockwood's (1999) framework, user roles are combined into user role maps revealing the interrelationships between the various roles. The present study revealed that the non-mobile professional was an abstraction of three sub-roles: internal communicator, in-office administrator/manager, and in-house operator. Since the non-mobile professional roles are mainly internally oriented, the PDA's date book assisting the administrator/operator sub-role is the most frequently used function. The mobile professional was an abstraction of four sub-roles: external communicator, business/sales developer, out of office administrator/manager, and field operator. The sub-roles of the mobile professional role are primarily oriented to the world outside the organization, for example, in contacting customers, developing business or building strategic partnerships. To support the various sub-roles of mobile professionals, communication functions supporting person-to-person contact are thus important, as shown in Figure 2.

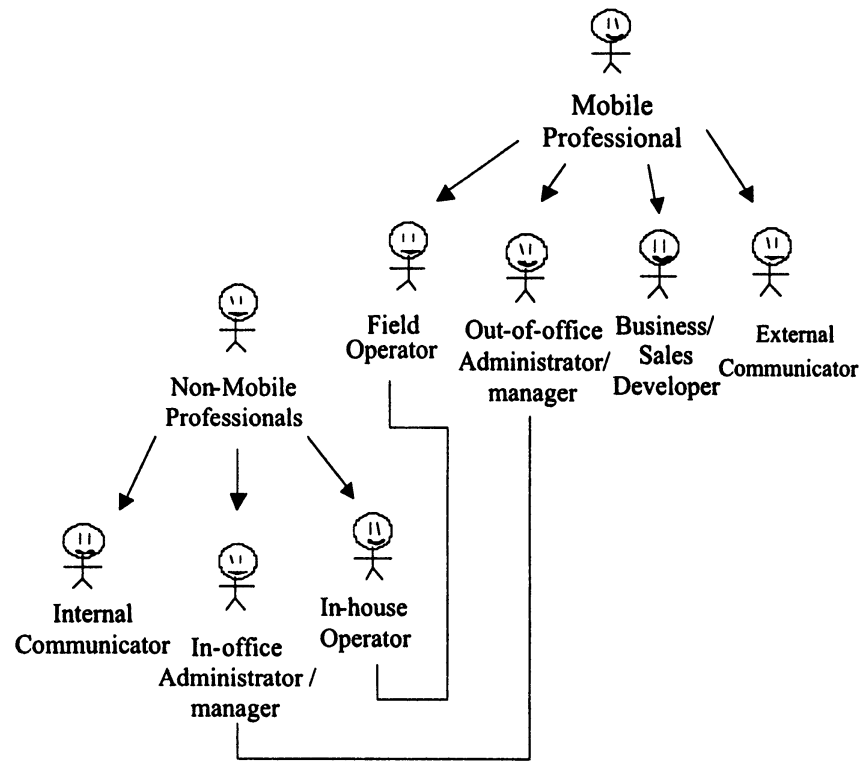

Figure 2. User Role Map For Mobile and Non-Mobile Roles (adapted from Constantine \& Lockwood, 1999) 
Some affinity or resemblance was noted between the in-office and out-ofoffice administrator/manager sub-roles as well as the in-house operator and field operator sub-roles.

It thus appears that the external communicator and business developer sub-roles differentiate the mobile professional role from the non-mobile professional role in relation to PDA usage. The external communicator subrole within the mobile professional role manifests itself in the more common use of PDAs with communication capabilities such as the Blackberry and cellular phone with e-mail and Internet access.

If users in the mobile role have PDAs with wireless connectivity, then they complete the rest of their role functions with a laptop computer. Those in the mobile role with a Palm handheld use the cellular phone and regular phone to complete their role functions. In this context, the wireless connectivity of PDAs emerges as an important function for the mobile role. Another key point of difference in the use of PDAs in the mobile role is the interaction between the date book, the address book, the e-mail, and the phone in a dynamic field setting. The interaction among the PDA functions makes it extremely important to interlink the functions, rendering easy changeover from one function to another possible.

\section{SUMMARY AND CONCLUSION}

The SUNA methodology outlined here proceeded from a broad of user/job types enunciated at the beginning of a brainstorming session to an abstraction of job/user types into user roles distinct in terms of needs, behaviour, expectations and job responsibilities. The method also allowed analysis based on formal job classification data. The characteristics of the user roles were clear enough to select two focal roles based on the objective of identifying early adopters of a technology that was still in its early stage of development. The methodology included testing on a small sample of users with an automatic logging system where possible. In the context of the $\log$, it was feasible to understand the PDA usage in relation to the user roles and sub-roles through an extensive face-to-face interview. Analysis of the collected information indicated that the difference and commonalties in PDA usage was related to the difference and commonalties in the sub-roles. The focus on user roles rather than on individual users supported a 'big picture' perspective on the one hand, while it also brought out important similarities and differences between the focal user roles investigated.

From a product development perspective, SUNA precedes a fully-fledged UNA in the sense that SUNA focuses on strategic identification and selection of functions and meta-functions for targeted user groups whereas 
UNA's focus is on analysing well-defined tasks and specific user profiles underlying detailed interface design.

The next steps are clearly to test and refine the SUNA methodology on larger samples for different user roles requiring wireless technologies, and to integrate it together with Usability Engineering into software and product development methodologies. It would be very interesting also to explore its conceptual usefulness in a complete Greenfield context in which the technology in question is at a concept stage.

\section{REFERENCES}

Beyer, H. \& Holtzblatt, K. (1998), Contextual Design: Defining Customer-Centered Systems, Morgan Kaufmann Publishers, Inc., San Francisco.

Constantine, L., \& Lockwood, L. (1999), Software for Use: A Practical Guide to the Models and Methods of Usage-Centered Design, ACM Press, New York.

Hackos, J.T. \& Redish, J.C. (1998), User And Task Analysis for Interface Design, John Wiley \& Sons, Inc. New York.

Kirwan, B. \& Ainsworth, L.K. (eds.) (1992), A Guide to Task Analysis, Taylor \& Francis, London.

Lindgaard, G. (1993), Wow - 568 smart features on your PABX: What really determines the uptake of technology? International Symposium Human Factors in Telecommunications Proceedings, Darmstadt, Germany, May 11-14.

Lindgaard, G. \& Ferguson, J. (1992), Value for money?: The wonderful world of versatile PABX systems, Telecom Research Laboratories Report NO. 8209.

Maguire, M. (1997), User-Requirements Framework Handbook, HUSAT Research Institute, Loughborough, UK.

Mayhew, D.J. (1999), The Usability Engineering Lifecycle: A Practitioner's Handbook For User Interface Design, Morgan Kaufman Publishers, San Francisco, CA.

Narasimhan, S. (2001), A User Needs Assessment for Personal Digital Assistants, Unpublished Honours Thesis, Department of Psychology, Carleton University, Ottawa, Canada.

Shepherd, A. (2001), Hierarchical Task Analysis, Taylor \& Francis, London.

Yankee Group, The. (August 1999), Wireless/Mobile Data Applied Vertically: A Business Segmentation Model, (Nortel Intranet). 